\title{
Cardiac Sympathetic Stimulation Increases Cardiac Contractility But Decreases Contractile Efficiency in Canine Hearts In Vivo
}

\author{
Takeshi Kudo, MD; Atsushi Mikuniya, MD; Naoyuki Suto, MD; \\ Tomoyuki Okubo, MD; Takeru Yamamoto, MD; Ken Okumura, MD
}

\begin{abstract}
The effect of cardiac sympathetic stimulation on cardiac contractile efficiency was studied in dogs. In 19 anesthetized and open-chest dogs, left ventricular (LV) pressure, LV volume, coronary blood flow and coronary venous oxygen saturation were measured simultaneously. The LV end-systolic pressure volume relations (ESPVR) and the relation between myocardial oxygen consumption $\left(\dot{\mathrm{V}}_{2}\right)$-pressure volume area (PVA) were obtained during a transient occlusion of the inferior vena cava before and after sympathetic stimulation $(9 \mathrm{~V}, 6$ $\mathrm{Hz}, 40 \mathrm{sec}$ ) both with and without $50 \mathrm{mg} / \mathrm{kg}$ of 2,3-butanedione monoxime (BDM). Without BDM, sympathetic stimulation increased the slope of ESPVR by $62 \%(\mathrm{p}<0.05)$, the slope of the $\mathrm{V}_{2}-\mathrm{PVA}$ line by $19 \%(\mathrm{p}<0.05)$ and the $\mathrm{y}$-axis intercept of the $\mathrm{VO}_{2}$-PVA by $65 \%(\mathrm{p}<0.05)$. With BDM, the increase in the slope of the $\dot{\mathrm{V}} \mathrm{O}_{2}$-PVA line became insignificant although other responses were similarly preserved. These data imply that cardiac sympathetic stimulation decreases cardiac contractile efficiency through mechanisms by which norepinephrineinduced $\beta$-adrenergic activation enhances myosin ATPase-operating ATP hydrolysis in crossbridge formation. (Jpn Circ J 1998; 62: 925-932)
\end{abstract}

Key Words: Crossbridges; Pressure-volume area; 2,3-butanedione monoxime

$\mathbf{S}$ tress to the sympathetic nerve system increases norepinephrine (NE) release from the postganglionic endings, inducing positive-chronotropic and -inotropic actions in the heart ${ }^{-3}$ The effects of NE on these actions are related to stimulation of $\beta$-adrenergic receptors at which cyclic AMP is increased in the myocardial cell as the primary second messenger for mediating the inotropic effects. Thus, it is indisputable that cardiac sympathetic stimulation modulates the mechanical augments of the frequency and force of the myocardium by way of $\beta$-adrenergic activation with NE release.-7 Recently, an experimental study showed that adrenaline increased the rate of cycling of actin-myosin crossbridges in cardiac muscle? This study suggested the possibility that each crossbridge can transduce energy at the increased rate of crossbridge cycling.

In the study of cardiac energetics, partitioning of total energy output into mechanical and nonmechanical components is a requisite approach. The pressure-volume area (PVA), proposed by Suga et al? is an expression of the total mechanical energy output (external work + potential energy) of ventricular contraction based on the timevarying elastance model $!^{10} \mathrm{PVA}$ has been proved to linearly relate to left ventricular $\mathrm{O}_{2}$ consumption $\left(\dot{\mathrm{V}}_{2}\right)$ per beat ${ }^{11}$ In the $\dot{\mathrm{V}} \mathrm{O}_{2}$-PVA relation, the $\dot{\mathrm{V}} \mathrm{O}_{2}$ for mechanical energy utilization is estimated as the 'excess' $\dot{\mathrm{V}} \mathrm{O}_{2}$ above the unloaded $\dot{\mathrm{V}} \mathrm{O}_{2}$, which is $\dot{\mathrm{V}} \mathrm{O}_{2}$ at $\mathrm{PVA}=0$. The $\dot{\mathrm{V}} \mathrm{O}_{2}$ for

(Received June 5, 1998; revised manuscript received August 5, 1998; accepted August 12, 1998)

Second Department of Internal Medicine, Hirosaki University School of Medicine, Hirosaki, Japan

Mailing address: Takeshi Kudo, MD, The Second Department of Internal Medicine, Hirosaki University School of Medicine, Zaifucho 5, Hirosaki 036, Japan nonmechanical energy utilization is represented as the $\dot{\mathrm{V}}_{2}$ axis intercept of the $\dot{\mathrm{V}} \mathrm{O}_{2}$-PVA line. The nonmechanical energy cost consisting of the $\dot{\mathrm{V}}_{2}$ for excitation-contraction (E-C) coupling and for basal metabolism has been demonstrated to be virtually independent of ventricular volume or PVA 11 Thus, the inverse slope of the linear $\dot{\mathrm{V}}_{2}-$ PVA relation, or the ratio of mechanical energy output (PVA) to chemical energy input ('excess' $\dot{V}_{2}$ ) is an expression of the efficiency of chemomechanical energy transduction by the contractile proteins when both $\dot{\mathrm{V}}_{2}$ and PVA are expressed in standard energy.

We examined the effect of cardiac sympathetic stimulation on the $\dot{\mathrm{V}} \mathrm{O}_{2}$-PVA relation with and without a low dose of 2,3-butanedione monoxime (BDM), which directly inhibits myocardial crossbridge formation of contractile proteins without affecting E-C coupling.12 Thus, we studied the effect of cardiac sympathetic stimulation on cardiac contractile efficiency in terms of actin-myosin crossbridge formation.

\section{Methods}

\section{Surgical Preparation}

Nineteen mongrel dogs, weighing $23.7 \pm 4.2 \mathrm{~kg}$ (mean \pm $\mathrm{SD}$ ), were used for the studies according to the guidelines established for animal experiments in Hirosaki University. The dogs were premedicated with a subcutaneous injection of xylazine $(4 \mathrm{mg} / \mathrm{kg})$ and atropine sulfate $(0.05 \mathrm{mg} / \mathrm{kg})$, and anesthetized with $\alpha$-chloralose $(100 \mathrm{mg} / \mathrm{kg})$ and pancronium bromide $(0.7 \mathrm{mg} / \mathrm{kg})$. Small supplemental doses of a -chloralose $(20 \mathrm{mg} / \mathrm{kg}$ per h) were continuously infused to each dog throughout the experiments. Under the anesthesia, the dogs were intubated and ventilated by a fixedvolume positive-pressure respirator (model 613, Harvard 
Apparatus, USA) with room air supplemented by $30 \%$ oxygen. Blood volume losses resulting from the surgery were supplemented with $6 \%$ dextran in normal saline before initiating the experimental protocol. With the animal in a supine position, the right femoral artery was isolated and a fluid-filled catheter (Cordis, USA) was inserted into the descending aorta to measure aortic pressure. An $8 \mathrm{~F}$ balloon catheter (Medi-tech, USA) was placed just below the right atrium through the right femoral vein to occlude the inferior vena cava briefly for measurement of the endsystolic pressure-volume relationship (ESPVR). A midline cervical incision was performed to expose the bilateral vagi and carotid arteries, and a 7F catheter-tip micromanometer (model PC 780 N, Millar, USA) was advanced through the left carotid artery into the left ventricular (LV) chamber for measurement of $\mathrm{LV}$ pressure. A $6 \mathrm{~F}$ conductance catheter (model 2-RE-218-B, The Netherlands) was also advanced through the right carotid artery and inserted into the LV chamber to measure LV volume. These catheters were positioned parallel to the long axis of the left ventricle. For the measurement of parallel conductance formed by surrounding tissue, a balloon-flotation catheter (Nihon Koden, Tokyo, Japan) was also inserted into the pulmonary artery through the right jugular vein.

The chest was opened midsternally. Both the left anterior descending (LAD) and left circumflex (LCX) coronary arteries were dissected free from the surrounding tissue before the first diagonal branch and ultrasound transit time flow probes (model T 206, Transonic System Inc, USA) were snugly applied around each coronary artery for measurement of coronary blood flow.

To measure coronary venous oxygen content $\left(\mathrm{CV}_{2}\right)$, we isolated a proximal portion of the coronary vein running along with the LAD. We made a bypass connection between the coronary vein and the left femoral vein with a 7F teflon tube (Kawasumi, Japan) and a perfusion pump (model AP-7000, Atto, Japan), allowing smooth insertion of a 3F fiberoptic catheter (Abbott Lab, USA) into the coronary vein for continuous measurement of oxygen saturation. The cardiac sympathetic nerve (CSN) stimulation model was the same as in our previous studies.6.7 Briefly, the right and left CSNs running from the stellate ganglia and cervical vagus nerves to the heart were exposed carefully and ligated tightly for transection. The left CSN was stimulated with bipolar pacing electrodes $(2 \mathrm{~ms}, 6 \mathrm{~Hz}, 9 \mathrm{~V})$ for a period of $40 \mathrm{~s}$ with an electrical stimulator (Nihon Koden, Japan). A pair of pacing electrodes was attached to the right auricular appendage for atrial pacing with a pacemaker (model EDP-20, Nihon Koden, Japan).

\section{Data Collection}

An 8-electrode conductance catheter (Leycom) with appropriate electrode distances and a Sigma 5 signal conditioner processor (Leycom) were used for measurement of left ventricular volume!3,14 Briefly, the conductance catheter method is based on measuring the time-varying electrical conductance of blood in 5 segments of the left ventricle. We estimated LV volume from blood conductivity of the left ventricle by applying an alternating current $(0.07 \mathrm{~mA}$ root-mean-square at $20 \mathrm{kHz})$ through the outer two electrodes and by measuring the time-varying electrical conductances of 5 segments among the inner 6 electrodes. A small bolus $(1 \mathrm{ml})$ of hypertonic saline $(6$ $\mathrm{mmol} / \mathrm{L}$ ) was injected through the balloon catheter into the pulmonary artery for parallel conductance measurement, which was required for calibration of this method. The LAD and the LCX coronary blood flow were continuously measured with ultrasound transit time flowmeters (model T 206, Transonic System Inc, NY, USA) and were corrected with the weight of the perfusion territory and expressed in $\mathrm{LV}$ flow ( $\mathrm{ml} /$ beat per $100 \mathrm{~g}$ ). The perfusion territory of the LAD and LCX coronary arteries was defined at the conclusion of the experiment by staining the area with methylene blue, and then sectioning and weighing it. Coronary venous oxygen saturation ( $\left.\mathrm{CV} \mathrm{O}_{2}-\mathrm{Sat}\right)$ was continuously measured with an oximeter (Oximetrix 3, Abbott Lab) using a fiberoptic catheter indwelling in the bypass tube between the coronary vein and femoral vein. This oximeter system displays successively an average of the oxygen saturation measured during the latest 5-s period. Furthermore, $\mathrm{CV}_{2}-$ Sat was measured in the bypass tube and not in the intraluminal or pericardial coronary vein, so that there seemed to be a time lag between the changes in the coronary venous oxygen saturation and $\mathrm{CVO}_{2}-\mathrm{Sat}$ measured in this study. Therefore, in the estimation of $\mathrm{CV}_{2}-S a t$, we corrected its time course so as to make the nadir of $\mathrm{CVO}_{2}-$ Sat during an occlusion of the inferior vena cava (IVC) coincide with that of the LV systolic pressure.

Throughout the experiments, ECG, LV volume, aortic pressure, LV pressure, LAD and LCX coronary flow, $\mathrm{CVO}_{2}-\mathrm{Sat}$ and $\mathrm{LV}$ pressure-volume loops were recorded on an 8-channel heat-stylus recorder (model WS-681G, Nihon Koden) and stored on magnetic tape using an analog tape recorder (model A614, Sony, Japan) for subsequent data processing. Blood gas values were checked every $30 \mathrm{~min}$ and kept within normal range by adjusting respiration or administering sodium bicarbonate.

Blood samples for the measurement of plasma NE concentration were obtained from the descending aorta with a catheter inserted from the femoral artery. Each blood sample $(5 \mathrm{ml})$ was immediately centrifuged $\left(4^{\circ} \mathrm{C}, 3000\right.$ $\mathrm{rpm}, 15 \mathrm{~min}$ ) by the centrifugal separator (model RL-100, Tomy, Japan), and kept frozen $\left(-20^{\circ} \mathrm{C}\right)$ until assays were performed. The plasma NE was separated by high-performance liquid chromatography and determined with automatic fluorescence analyzer (model HLC-725CA, Toso, Japan).

\section{Experimental Protocol}

Before initiating the experiment, we paced the hearts of all 19 dogs at the rate of $10 \%$ higher than their spontaneous beats and kept the paced beats as the basic rate throughout the experiments. In the condition of stabilized hemodynamics, a transient occlusion of the IVC was performed by inflating a balloon catheter while recording ECG leadII, LV volume, aortic pressure, LV pressure, LAD and LCX coronary flow, and $\mathrm{CV} \dot{O}_{2}-$ Sat. Similarly, the IVC occlusion was repeated $1 \mathrm{~min}$ after stimulation of the left CSN with the electrical stimulator $(9 \mathrm{~V}, 1 \mathrm{~ms}$-pulse width) for a train duration of $40 \mathrm{~s}$ at a frequency of $6 \mathrm{~Hz}$ ('Without BDM measurements').

After the experiment without BDM, a dose of $50 \mathrm{mg} / \mathrm{kg}$ of BDM (Sigma, USA) diluted with $10 \mathrm{ml}$ of normal saline was intravenously infused over $1 \mathrm{~min}$. Four minutes after BDM infusion, when systemic hemodynamics had mostly recovered to the level before BDM infusion, a transient occlusion of the IVC was similarly repeated before and after the electrical sympathetic stimulation ('With BDM measurements').

Plasma NE concentration (in $8 \mathrm{dogs}$ ) was measured 


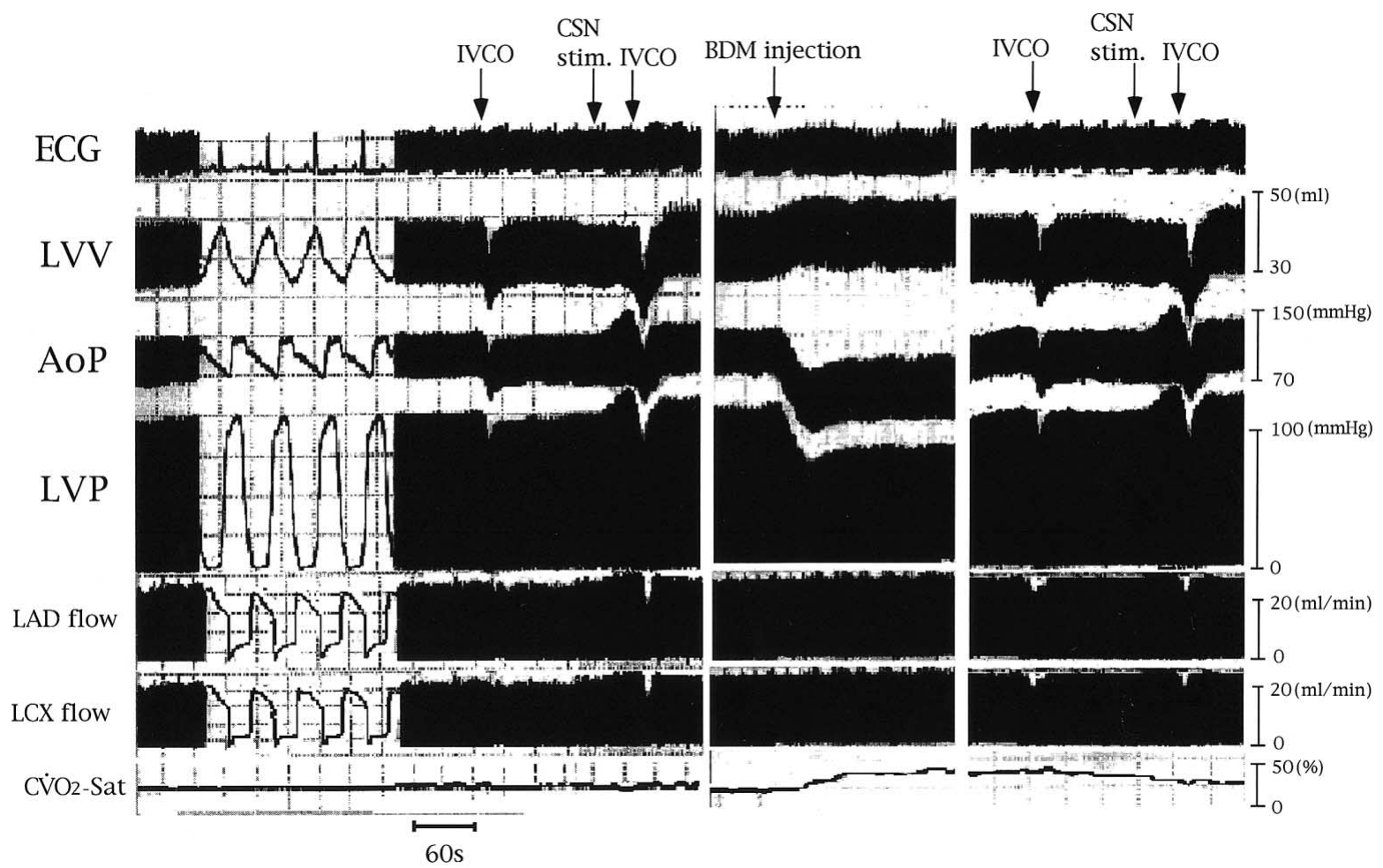

Fig 1. Representative recordings and experimental protocols from one heart. Cardiac sympathetic nerve (CSN) stimulation $(6 \mathrm{~Hz}, 9 \mathrm{~V}$, $40 \mathrm{~s}$ ) increased aortic pressure (AoP), left ventricular pressure (LVP) and coronary flow. Low-dose BDM decreased AoP, LVP and coronary flow. Low-dose BDM transiently increased LV volume (LVV). ECG, electrocardiogram; LAD flow, flow of the left anterior descending coronary artery; LCX flow, flow of the left circumflex coronary artery; $\mathrm{CV}_{2}$-Sat, oxygen saturation of the coronary vein; IVCO, inferior vena cava occlusion to obtain end-systolic pressure volume relation; BDM injection, intravenous injection of 2,3-butanedione monoxime.

before and after the CSN stimulation without BDM, immediately before BDM infusion, and before and after CSN stimulation with BDM.

At the conclusion of the experiment, the dogs were euthanized with injection of potassium chloride $(0.04 \mathrm{~mol} / \mathrm{L})$ and the basal metabolism was measured.

\section{Data Analysis}

All data stored on the magnetic tape were digitized. The sample frequency for A-D conversion was $200 \mathrm{~Hz}$ at 12-bit accuracy. Data of the systemic hemodynamics were analyzed by the acquisition-archive-system (Po-Ne-Mah, USA), and that of the LV pressure-volume loops by the pressure-volume analysis program (Cardio-Dynamics, The Netherlands). ESPVR was determined by linear regression of the individual end-systolic points in the combined LV pressure-volume loops. Then, the slope of the ESPVR (Emax) during a transient IVC occlusion was calculated. PVA was obtained as the specific area in the pressurevolume diagram circumscribed by the ESPVR line, the end-diastolic pressure volume curve and the systolic segment of the pressure volume trajectory. With values of hemoglobin $(\mathrm{Hb})$, coronary arterial oxygen saturation $\left(\mathrm{CAO}_{2}-\mathrm{Sat}\right), \mathrm{CVO}_{2}-\mathrm{Sat}$ and $\mathrm{LV}$ coronary flow, the coronary arteriovenous oxygen content difference $\left(\mathrm{A}-\mathrm{VDO}_{2}\right)$ and $\dot{\mathrm{V}}_{2}$ per beat were calculated by the formulas, respectively:

$$
\begin{aligned}
& \mathrm{A}-\mathrm{VDO}_{2}\left(\mathrm{vol}^{2}\right)= \\
& \quad\left(\mathrm{CAO}_{2}-\mathrm{Sat}-\mathrm{CVO}_{2}-\mathrm{Sat}\right) \times 10^{-2} \times 1.34 \times \mathrm{Hb}(\mathrm{g} / \mathrm{dl})
\end{aligned}
$$

$\mathrm{VO}_{2}$ per beat $\left(\mathrm{mlO}_{2} /\right.$ beat per $\left.100 \mathrm{~g}\right)=$ $\left(\mathrm{A}-\mathrm{VDO}_{2}\right) \times 10^{-2} \times \mathrm{LV}$ flow $(\mathrm{ml} / \mathrm{min}) / \mathrm{HR}$

The $\dot{\mathrm{V}} \mathrm{O}_{2}-\mathrm{PVA}$ relation was constructed by the $\dot{\mathrm{V}} \mathrm{O}_{2}$ per beat against the PVA. We obtained the cardiac contractile efficiency (\%) from the ratio of PVA to $\mathrm{VO}_{2}$, both in $\mathrm{J} /$ beat per $100 \mathrm{~g}\left(\dot{\mathrm{VO}}_{2}\right.$ in $\mathrm{mlO}_{2} /$ beat per $100 \mathrm{~g}$ and PVA in $\mathrm{mmHg}$ $\mathrm{ml} /$ beat per $100 \mathrm{~g}$ can be converted to $\dot{\mathrm{VO}}_{2}$ and PVA both in the same unit of energy of J/beat per $100 \mathrm{~g}){ }^{15,16}$

All data are shown as mean $\pm \mathrm{SD}$. ANOVA was applied to compare the $\dot{\mathrm{V}} \mathrm{O}_{2}-\mathrm{PVA}$ line before and after CSN stimulation. Changes in systemic hemodynamics, Emax, and the slope and the y-axis intercept of the $\mathrm{VO}_{2}$-PVA line were compared by two-way repeated measure analysis of variance (two-way RM-ANOVA). If the two-way ANOVA was statistically significant, then the Student-NewmanKeuls test was applied. Values were considered statistically significant when $\mathrm{p}<0.05$.

\section{Results}

Fig 1 shows representative analog recordings of ECG leadII, LV volume, aortic pressure, LV pressure, LAD and LCX coronary flow, and $\mathrm{CVO}_{2}-$ Sat throughout this study. The left panel shows systemic and coronary hemodynamics without BDM, the middle panel shows changes in hemodynamics immediately after BDM, and the right panel shows systemic and coronary hemodynamics 4 min after BDM. Note that the systemic and coronary hemodynamics, except $\mathrm{CV} \mathrm{O}_{2}-\mathrm{Sat}$, are almost equal in two conditions: without 
Table 1 Effects of Cardiac Sympathetic Nerve Stimulation on Systemic Hemodynamics and Cardiac Mechanics

\begin{tabular}{ccccccc}
\hline \hline & $\begin{array}{c}H R \\
(\text { beats/min })\end{array}$ & $\begin{array}{c}\text { LVESP } \\
(\mathrm{mmHg})\end{array}$ & $\begin{array}{c}\text { LVEDP } \\
(\mathrm{mmHg})\end{array}$ & $\begin{array}{c}\text { LVESV } \\
(\mathrm{ml})\end{array}$ & $\begin{array}{c}\text { LVEDV } \\
(\mathrm{ml})\end{array}$ & $\begin{array}{c}\text { Emax } \\
(\mathrm{mmHg} / \mathrm{ml})\end{array}$ \\
\hline $\begin{array}{c}\text { Control }(\mathrm{n}=19) \\
\text { pre-stim }\end{array}$ & $106.9 \pm 18.1$ & $96.0 \pm 7.0$ & $11.9 \pm 4.5$ & $33.1 \pm 3.1$ & $47.6 \pm 6.2$ & $3.64 \pm 0.90$ \\
$\quad$ CSN-stim & $111.2 \pm 17.5$ & $117.8 \pm 8.8^{*}$ & $10.8 \pm 4.6$ & $32.6 \pm 7.1$ & $46.3 \pm 10.6$ & $5.91 \pm 2.25^{*}$ \\
$\begin{array}{c}\text { BDM }(n=19) \\
\text { pre-stim }\end{array}$ & & & & & & \\
CSN-stim & $123.9 \pm 30.2$ & $93.5 \pm 9.8$ & $12.1 \pm 4.5$ & $33.7 \pm 5.6$ & $46.1 \pm 4.8$ & $3.54 \pm 0.56$ \\
& $125.9 \pm 32.5$ & $109.6 \pm 12.1^{*}$ & $11.9 \pm 4.4$ & $29.9 \pm 5.5$ & $42.9 \pm 6.1$ & $5.58 \pm 0.98^{*}$ \\
\hline
\end{tabular}

Values are mean $\pm S D ; B D M, 2,3$-butanedione monoxime; pre-stim, pre-stimulation; CSN-stim, left cardiac sympathetic nerve stimulation; HR, heart rate; LVESP, left ventricular end-systolic pressure; LVEDP, left ventricular end-diastolic pressure; LVESV. left ventricular end-systolic volume; LVEDV, left ventricular end-diastolic volume; Emax, the slope of the end-systolic pressurevolume line.

${ }^{*} p<0.05$ compared with pre-stimulation value of each study.

Table 2 Effects of Cardiac Sympathetic Nerve Stimulation on Cardiac Energetics

\begin{tabular}{|c|c|c|c|c|c|c|}
\hline & $\begin{array}{c}P V A \\
(\mathrm{mmHg} \cdot \mathrm{ml} / \mathrm{beat} / 100 \mathrm{~g})\end{array}$ & $\begin{array}{c}C B F \\
(\mathrm{ml} / \mathrm{min} / 100 \mathrm{~g})\end{array}$ & $\begin{array}{c}A-\mathrm{VDO}_{2} \\
(\mathrm{mlO} / \mathrm{O} / 100 \mathrm{ml})\end{array}$ & $\begin{array}{c}\dot{\mathrm{V}} \mathrm{O}_{2} \\
(\mathrm{mlO} / \text { beat } / 100 \mathrm{~g})\end{array}$ & $\begin{array}{l}y \text {-axis intercept }\left(\times 10^{-2}\right. \\
(\mathrm{mlO} / \mathrm{O} / \mathrm{beat} / 100 \mathrm{~g})\end{array}$ & -2) $\begin{array}{c}\text { slope }\left(\times 10^{-5}\right) \\
(\mathrm{mlO} / \mathrm{mmHg} \cdot \mathrm{ml})\end{array}$ \\
\hline \multicolumn{7}{|c|}{ Control $(n=19)$} \\
\hline pre-stim & $2720 \pm 492$ & $60.8 \pm 16.8$ & $12.7 \pm 2.0$ & $0.067 \pm 0.015$ & $2.28 \pm 0.53$ & $1.62 \pm 0.25$ \\
\hline CSN-stim & $3250 \pm 593 *$ & $82.4 \pm 20.9 *$ & $13.8 \pm 2.2 *$ & $0.094 \pm 0.016^{*}$ & $3.57 \pm 0.56^{*}$ & $1.91 \pm 0.23 *$ \\
\hline \multicolumn{7}{|l|}{$B D M(n=19)$} \\
\hline pre-stim & $2512 \pm 459$ & $59.3 \pm 23.4$ & $11.1 \pm 2.6^{\dagger}$ & $0.056 \pm 0.015^{\dagger}$ & $1.79 \pm 0.60^{\dagger}$ & $1.41 \pm 0.21^{\dagger}$ \\
\hline CSN-stim & $3003 \pm 485 *$ & $76.0 \pm 24.2 *$ & $12.2 \pm 2.3 *$ & $0.077 \pm 0.014 *$ & $2.96 \pm 0.66^{*}$ & $1.48 \pm 0.23$ \\
\hline
\end{tabular}

Values are mean $\pm S D ; B D M, 2,3$-butanedione monoxime; pre-stim, pre-stimulation; CSN-stim, left cardiac sympathetic nerve stimulation; PVA pressure volume area; $C B F$, left ventricular coronary blood flow; $A-V D O 2$, coronary arterio-venous oxygen content difference; $\dot{V} O_{2}$, left ventricular oxygen consumption; $y$-axis intercept, the y-axis intercept of the $P V A-\dot{V} O_{2}$ relation; slope, the slope of the $\mathrm{PVA}-\mathrm{VO}_{2}$ relation.

${ }^{*} p<0.05$ compared with pre-stimulation value of each study. ${ }^{*} p<0.05$ compared with pre-stimulation value of control.

A
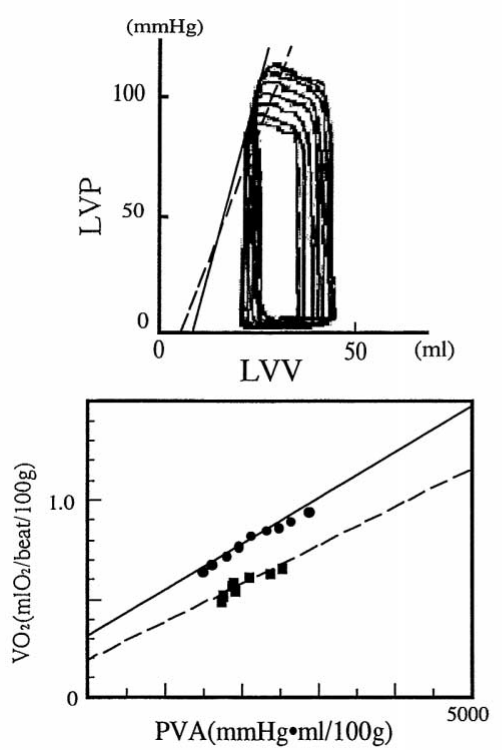

B
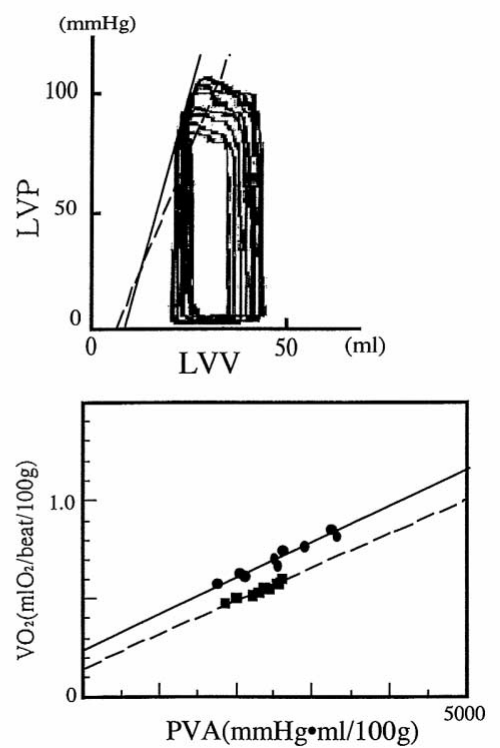

Fig 2. An example of the pressurevolume loop and the $\dot{\mathrm{V}} \mathrm{O}_{2}-\mathrm{PVA}$ relation in the control study (A), in the BDM study (B). Solid line indicates the endsystolic pressure volume relation (ESPVR) and the $\dot{\mathrm{V}} \mathrm{O}_{2}$-PVA relation after CSN stimulation (A). Dashed line indicates the ESPVR and the $\dot{\mathrm{V}} \mathrm{O}_{2}$-PVA relation of before CSN stimulation (B). CSN stimulation increased Emax regardless of BDM administration. It also increased the $y$-axis intercept of the $\dot{\mathrm{V}} \mathrm{O}_{2}$-PVA relation, but there was little increase of the slope of the $\dot{\mathrm{V}} \mathrm{O}_{2}$-PVA relation after administration of BDM. Emax: after CSN stimulation (before CSN stimulation): (A) $7.6(4.1) \mathrm{mmHg} / \mathrm{ml}$, (B) 6.5 (3.5) $\mathrm{mmHg} / \mathrm{ml}$. $\dot{\mathrm{V}} \mathrm{O}_{2}-\mathrm{PVA}$ relation: after CSN stimulation (before CSN stimulation):

(A) $\mathrm{y}=2.11 \times 10^{-5} \mathrm{X}+3.14 \times 10^{-2}$ $\left(\mathrm{y}=1.75 \times 10^{-5} \mathrm{X}+1.97 \times 10^{-2}\right)$

(B) $\mathrm{y}=1.76 \times 10^{-5} \mathrm{X}+2.35 \times 10^{-2}$ $\left(\mathrm{y}=1.66 \times 10^{-5} \mathrm{X}+1.56 \times 10^{-2}\right)$
BDM (left panel) and 4 min after BDM (right panel). In these conditions, the CSN stimulation similarly increased aortic pressure, LV pressure, and LAD and LCX coronary flow. The IVC occlusion transiently decreased LV volume, aortic pressure, LV pressure, and LAD and LCX coronary flow. The LV pressure-volume loops and analyzed $\dot{\mathrm{VO}}_{2}-$ PVA relations are displayed in Fig 2. Although sympathetic stimulation increased the slope of ESPVR in both conditions without BDM (Fig 2A) and with BDM (Fig 2B), the increase in the slope of the $\mathrm{VO}_{2}-\mathrm{PVA}$ relation by sympathetic stimulation became less with BDM than without BDM, suggesting a BDM-related effect on cardiac energetics. 
Systemic Hemodynamics and Cardiac Mechanics

Table 1 summarizes changes in the systemic hemodynamics and cardiac mechanics in all 19 dogs. In the condition without BDM, CSN stimulation increased the heart rate by $57 \%$ from $106.9 \pm 18.1$ beats $/ \mathrm{min}$ at the basic rate to $167.4 \pm 38.1$ beats $/ \mathrm{min}(\mathrm{p}<0.05)$ immediately after termination of the stimulation. The heart rate recovered to $111.2 \pm 17.5$ beats $/ \mathrm{min}$ at $1 \mathrm{~min}$ after the termination. With identical heart rates, CSN stimulation increased LV endsystolic pressure by $23 \%(\mathrm{p}<0.05)$ but induced no significant changes in LV end-diastolic pressure, LV end-diastolic volume or LV end-systolic volume. Thus, CSN stimulation increased Emax by $62 \%$ from $3.64 \pm 0.90 \mathrm{mmHg} / \mathrm{ml}$ to $5.91 \pm 2.25 \mathrm{mmHg} / \mathrm{ml}(\mathrm{p}<0.05)$.

Intravenous infusion of $50 \mathrm{mg} / \mathrm{kg}$ of BDM transiently deteriorated systemic hemodynamics and cardiac mechanics, but changes in heart rate, LV end-diastolic pressure, LV end-systolic pressure and LV end-systolic volume became insignificant by $4 \mathrm{~min}$ after BDM infusion. Then, the Emax, at $3.54 \pm 0.56 \mathrm{mmHg} / \mathrm{ml}$, was similar with that in the condition without BDM $(3.64 \pm 0.90 \mathrm{mmHg} / \mathrm{ml})$, and the responses of the systemic hemodynamics and cardiac mechanics to CSN stimulation were preserved. CSN stimulation at 4 min after BDM similarly increased the heart rate by $50 \%$ from $123.9 \pm 30.2$ beats $/ \mathrm{min}$ at the basic rate to $185.7 \pm 30.3$ beats $/ \mathrm{min}(\mathrm{p}<0.05)$ immediately after the stimulation, recovering to $125.9 \pm 32.5$ beats/min at $1 \mathrm{~min}$ after the stimulation. The increment of Emax by CSN stimulation was $58 \%$, similar with that of $62 \%$ in the control condition, and there was no significant difference of the increment. Accordingly, the low dose of BDM used in this study did not show a significant influence on the response of cardiac contractility to CSN stimulation.

\section{Cardiac Energetics}

The effects of CSN stimulation on cardiac energetics in all 19 dogs are summarized in Table 2 and Figs 3 and 4. Each $\dot{\mathrm{V}} \mathrm{O}_{2}$-PVA line constructed before and after CSN stimulation under the conditions without and with BDM showed a highly linear correlation coefficient $(r=0.96 \pm$ 0.01 ).

CSN stimulation in the control condition increased PVA by $21 \%(\mathrm{p}<0.05)$, coronary blood flow by $36 \%(\mathrm{p}<0.05)$, and coronary arteriovenous oxygen content difference by $8 \%(\mathrm{p}<0.05)$. The resultant $\dot{\mathrm{V}} \mathrm{O}_{2}$-PVA line after CSN stimulation shifted upward with increases in the slope and the $y$-axis intercept. The increments of the slope and the $y$-axis intercept were $19 \%(\mathrm{p}<0.05)$ and $59 \%(\mathrm{p}<0.05)$, respectively (Table 2, Figs 3,4 ). Therefore, CSN stimulation increased not only the $\mathrm{VO}_{2}$ for the work-unloaded portion but also the $\dot{\mathrm{V}} \mathrm{O}_{2}$ for the given work portion.

After BDM infusion, the arteriovenous oxygen content difference decreased while PVA and coronary blood flow did not change significantly. This decrease was $12.8 \%$ $(\mathrm{p}<0.05)$. The resultant $\dot{\mathrm{V}} \mathrm{O}_{2}$-PVA line with BDM shifted downward, showing a $13 \%(\mathrm{p}<0.05)$ decrease in the slope and a $22 \%(\mathrm{p}<0.05)$ decrease in the $\mathrm{y}$-axis intercept. When activated with CSN stimulation at $4 \mathrm{~min}$ after BDM, PVA increased by $20 \%(\mathrm{p}<0.05)$. Coronary blood flow and the coronary arteriovenous oxygen content difference increased by $31 \%(\mathrm{p}<0.05)$ and by $12 \%(\mathrm{p}<0.05)$, respectively. In addition, CSN stimulation increased the $y$-axis intercept of the $\dot{\mathrm{V}} \mathrm{O}_{2}$-PVA line by $70 \%(\mathrm{p}<0.05)$. However,

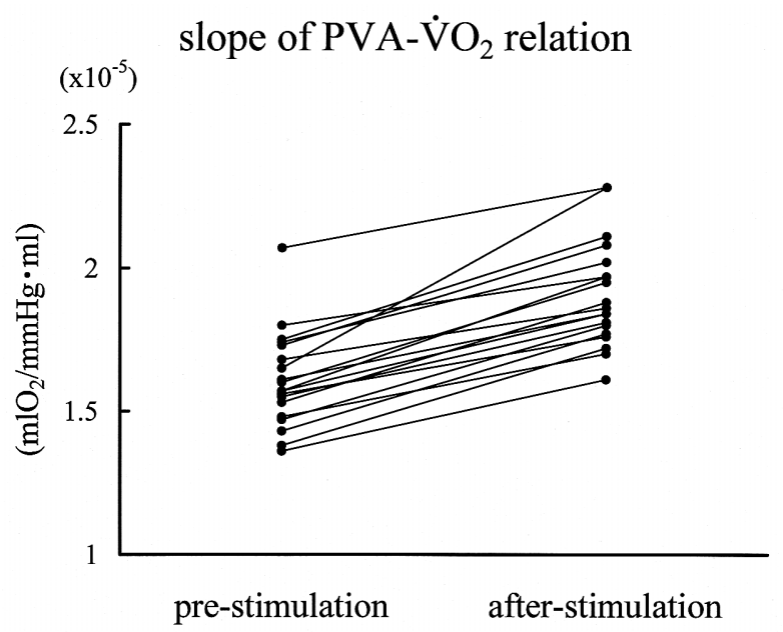

Fig 3. Solid lines represent the change of the slope of the $\dot{\mathrm{V}} \mathrm{O}_{2}-\mathrm{PVA}$ relation by cardiac sympathetic nerve (CSN) stimulation in each dog $(n=19)$. Pre-stimulation, before CSN stimulation; after-stimulation, after CSN stimulation.

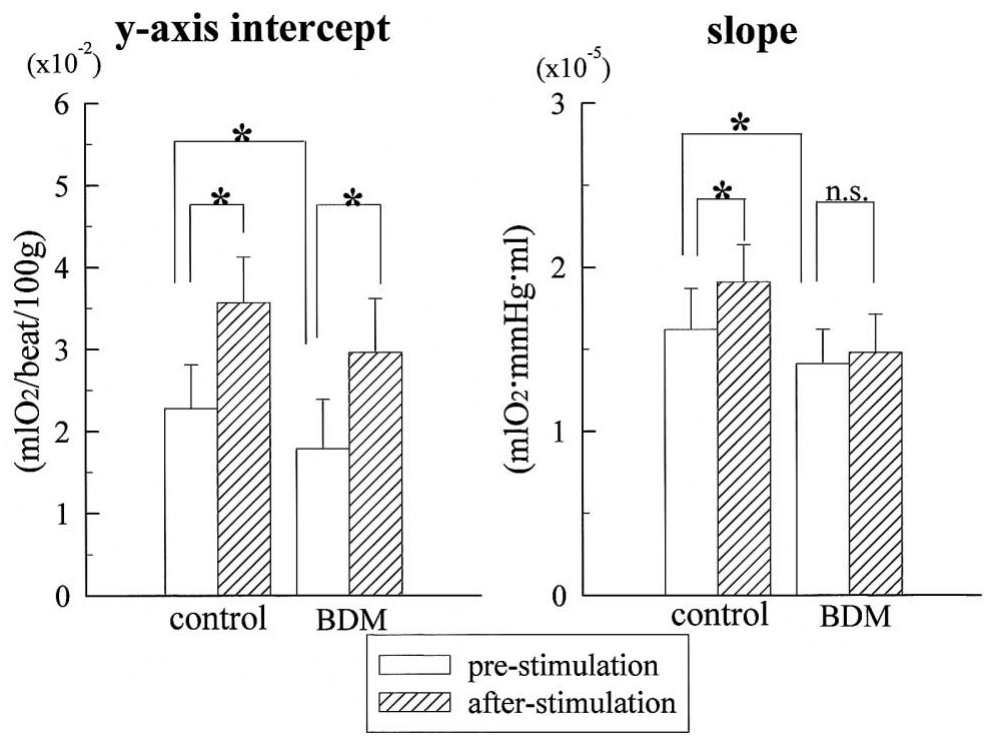

Fig 4. Bar graphs showing the yaxis intercept (left) and the slope of the $\dot{\mathrm{V}} \mathrm{O}_{2}$-PVA relation in each stage. Cardiac sympathetic nerve (CSN) stimulation increased the yaxis intercept also in the BDMpretreated condition but the increase of the slope by CSN stimulation was suppressed in the BDMpretreated condition, although CSN stimulation increased the slope in the control condition $(n=19)$. Data are expressed as mean \pm SD. BDM, after 2,3-butanedione monoxime injection; pre-stimulation, before CSN stimulation; after-stimulation, after CSN stimulation. ${ }^{*} \mathrm{p}<0.05$, n.s., not significant. 

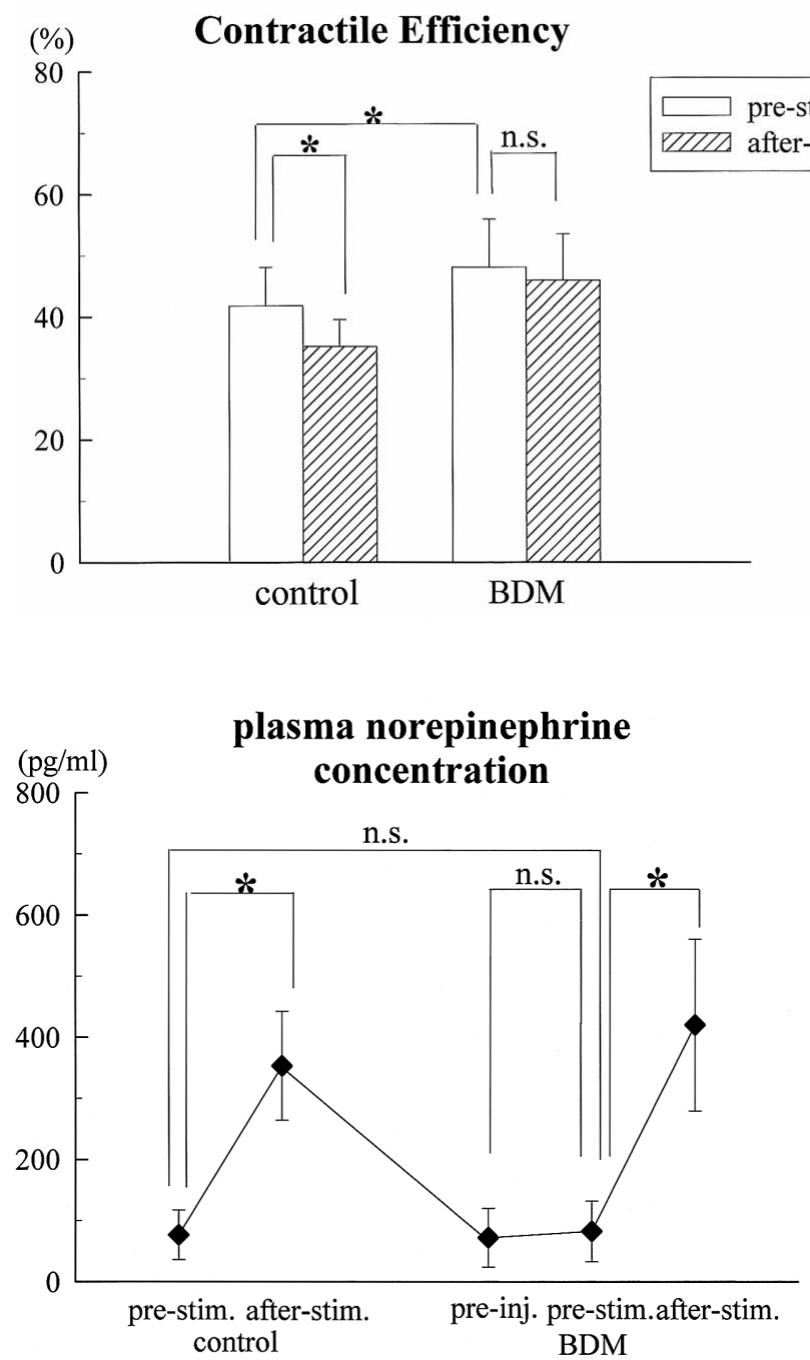

Fig 6. Solid line represents the change of the arterial norepinephrine (NE) concentration through all the stages. Cardiac sympathetic nerve (CSN) stimulation increased NE concentration regardless of 2,3butanedione monoxime (BDM) administration $(n=8)$. Data are expressed as mean \pm SD. Pre-stim., before CSN stimulation; afterstim., after CSN stimulation; pre-inj., just before BDM injection; control, control study; BDM: after BDM injection. *p $<0.05$ compared with before CSN stimulation value, n.s., not significant.

the response of the slope of the $\dot{\mathrm{V}} \mathrm{O}_{2}-\mathrm{PVA}$ line to CSN stimulation was not similar with that in the control condition; that is, the slope increment was only $5 \%$ and significantly lower $(\mathrm{p}<0.05)$ than that in the control condition. Accordingly, BDM suppressed the response of the $\dot{\mathrm{V}}_{2}$ for given work to CSN stimulation but not the $\dot{\mathrm{V}} \mathrm{O}_{2}$ for workunloaded.

\section{Cardiac Contractile Efficiency}

Fig 5 depicts changes in contractile efficiency due to CSN stimulation and the effect of BDM on contractile efficiency changes. In the control condition, contractile efficiency significantly decreased from $41.8 \pm 6.3 \%$ before CSN stimulation to $35.2 \pm 4.4 \%(\mathrm{p}<0.05)$ after CSN stimulation, showing a $16 \%$ decrease. Intravenous infusion of low dose BDM itself changed to $48.1 \pm 7.8 \%(\mathrm{p}<0.05)$, showing a $14 \%$ increase from that in the control condition. However, contractile efficiency after CSN stimulation was
Fig 5. Bar graphs showing the contractile efficiency in each stage. Cardiac sympathetic nerve (CSN) stimulation decreased contractile efficiency in the control condition, but there was no statistical change by CSN stimulation after pre-treatment with low-dose BDM $(n=19)$. Data are expressed as mean $\pm \mathrm{SD}$. Control, control study; BDM, after 2,3-butanedione monoxime injection; pre-stimulation, before CSN stimulation; afterstimulation, after CSN stimulation. ${ }^{*} \mathrm{p}<0.05$, n.s., not significant.

$46.0 \pm 7.6 \%$ and similar with that before CSN stimulation in the BDM pre-treated condition. A CSN stimulation-evoked decrease in contractile efficiency became negligible after BDM administration.

\section{Norepinephrine Concentration}

Fig 6 shows NE concentrations in the arterial plasma in 8 dogs in the control and BDM-pretreated conditions. In the control condition, CSN stimulation increased plasma NE concentration by $358 \%(\mathrm{p}<0.05)$ from $76.8 \pm 40.7 \mathrm{pg} / \mathrm{ml}$ before stimulation to $353.4 \pm 89.1 \mathrm{pg} / \mathrm{ml} 1 \mathrm{~min}$ after stimulation, recovering to the base level immediately before BDM infusion. After BDM infusion, NE concentration slightly increased to $82.6 \pm 49.4 \mathrm{pg} / \mathrm{ml}$ but was not significantly different from that before BDM. CSN stimulation after BDM similarly increased NE concentration to 420.4 \pm 140.6 $\mathrm{pg} / \mathrm{ml}$ with $406 \%$ increment $(\mathrm{p}<0.05)$. Thus, BDM did not influence plasma NE concentrations evoked by CSN stimulation.

\section{Discussion}

The major findings of the present study were as follows: (1) a $40 \mathrm{~s}$ train of CSN stimulation decreased cardiac contractile efficiency while augmenting cardiac contractility, and (2) the decrease in cardiac contractile efficiency on the CSN stimulation was inhibited by a low dose of BDM, whereas the responses of cardiac mechanical performance to the stimulation were similar before and after BDM. These observations raise the possibility that an increased NE release from CSNs may decrease cardiac contractile efficiency through mechanisms in which BDM operates inhibitorily. To provide a perspective for our results, several aspects of the methodology for the beat-by-beat analysis of the $\dot{\mathrm{V}} \mathrm{O}_{2}-\mathrm{PVA}$ relation during rapid IVC occlusion, and the effects of BDM on E-C coupling and cardiac contractile proteins, should be considered.

Based on the concept of the $\dot{\mathrm{V}} \mathrm{O}_{2}-\mathrm{PVA}$ relation developed in isolated heart experiments, the inverse slope of the $\dot{\mathrm{VO}} 2-\mathrm{PVA}$ line reflects cardiac contractile efficiency, and the $\dot{\mathrm{V}} \mathrm{O}_{2}$ axis intercept reflects the energy used for basal metabolism and E-C coupling. ${ }^{17}$ However, it is not known whether the relation developed in the isolated heart applies to the intact left ventricle ejecting into the circulation of conscious animals or humans. Nozawa et al studied this problem in conscious dogs and found that $\dot{\mathrm{V}}_{2}$ and PVA 
were linearly related during steady-state alterations in loading conditions in conscious dogs, but not on a beat-bybeat basis during transient caval occlusion!8 Assuming a constant coronary arteriovenous oxygen content difference on a transient caval occlusion, they compared the $\dot{\mathrm{V}} \mathrm{O}_{2}$ PVA relation during a transient caval occlusion with the relation under steady-state conditions, and found that the transient-occlusion $\dot{\mathrm{V}} \mathrm{O}_{2}-\mathrm{PVA}$ relation analyzed beat-bybeat was less linear and not coincident with the steadycondition $\dot{\mathrm{V}} \mathrm{O}_{2}$-PVA relation after the initial $2-4$ beats. However, the arteriovenous oxygen content difference tended to increase during transient caval occlusion in their study. Therefore, in the present study, we continuously measured $\mathrm{CV}_{2}$-Sat using the opticath oximetry system, which enabled beat-by-beat analysis of the coronary arteriovenous oxygen difference. The opticath system, together with the conductance catheter system, allowed us to obtain the immediate, beat-by-beat $\dot{\mathrm{V}} \mathrm{O}_{2}$ coincident with the PVA during transiently altered LV loading conditions, and in this study in dogs, the $\dot{\mathrm{V}} \mathrm{O}_{2}-\mathrm{PVA}$ relation during a transient caval occlusion was considerably linear on a beat-by-beat basis.

The isolated heart experiments have shown that catecholamines increase the unloaded $\dot{\mathrm{V}} \mathrm{O}_{2}$ but not the slope of the $\mathrm{VO}_{2}$-PVA line ${ }^{19}$ Most of the inotropic agents, including catecholamines, digitalis, propranolol and calcium channel-blockers, are considered to predominantly or exclusively exert their inotropic effects by changing the amount of intracellular $\mathrm{Ca}^{2+}$ available via E-C

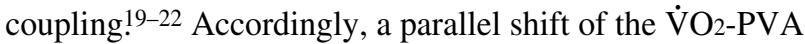
relation is exactly what would be anticipated with these types of interventions. However, the sympathetic stimulation in the present study slightly but significantly increased the slope of the $\dot{\mathrm{V}} \mathrm{O}_{2}$-PVA relation as well as the $\dot{\mathrm{V}} \mathrm{O}_{2}$ intercept, which suggested a reduction of cardiac contractile efficiency on cardiac sympathetic stimulation, because the inverse slope of the $\mathrm{VO}_{2}-\mathrm{PVA}$ relation reflects the extent of cardiac contractile efficiency. Consistent with our finding, Nozawa et al have shown that dobutamine increases not only the $\dot{\mathrm{V}} \mathrm{O}_{2}$ intercept but also the slope of the $\dot{\mathrm{V}} \mathrm{O}_{2}-\mathrm{PVA}$ relation. 3 They suggested $\beta$-adrenergic modulation of cardiac contractile efficiency 24 Furthermore, it has recently been demonstrated in rat myocardium that adrenaline increases the rate of cycling of actin-myosin crossbridges? The increase in the actin-myosin crossbridge cycling may need the increase in myosin ATPase activity. Thus, it was hypothesized that $\beta$-adrenergic activation on cardiac sympathetic stimulation reduces cardiac contractile efficiency by increasing myosin ATPase activity.

To test the hypothesis, we used a low dose of BDM, which selectively inhibits the enhancement of crossbridge formation. BDM is a nucleophilic agent and possesses phosphatase-like activity. It acts as a rapid, reversible negative inotropic drug by way of inhibiting ATP hydrolysis by myosin ATPase. 25 It has been reported that in isolated papillary muscle a low concentration of $\mathrm{BDM}(\leq 5 \mathrm{mmol} / \mathrm{L})$ decreased isometric twitch tension without altering tension independent heat, indicating the predominant effect of a low dose of BDM on the contractile proteins. ${ }^{12}$ In the present study, a dose of BDM below $5 \mathrm{mmol} / \mathrm{L}$ suppressed the decrease in contractile efficiency by cardiac sympathetic stimulation, which implies that CSN stimulation decreases contractile efficiency partly by enhanced crossbridge formation. Therefore, it is likely that $\beta$-adrenergic activation on cardiac sympathetic stimulation reduces cardiac contractile efficiency by increasing ATPase activity.

However, two methodological limitations in this study must be considered. First, there may be a possibility that BDM affected not only the contractile proteins but also E$\mathrm{C}$ coupling. We did not measure the plasma concentration of BDM in this study. However, we assumed that the concentration of BDM might be under $5 \mathrm{mmol} / \mathrm{L}$ during the experiments because $50 \mathrm{mg} / \mathrm{kg}$ of BDM was intravenously infused and was saturated to the systemic circulation (predictive concentration is about $5 \mathrm{mmol} / \mathrm{L}$ ). Then it would be rapidly resolved. Recent studies show that BDM suppressed E-C coupling even under low concentration? ${ }^{26-28}$ Concerning this point, the increase of the slope was suppressed under the BDM conditions in the present study, while the increase of the unloaded $\dot{\mathrm{VO}}_{2}$ on cardiac sympathetic stimulation was preserved, even after BDM infusion, with a slight decrement of unloaded $\mathrm{V}_{2}$. These results suggest that the change in the slope during CSN stimulation might be due to crossbridge formation.

Second, the effect of BDM on NE release during cardiac sympathetic stimulation should be noted. As shown in the results of this study, plasma NE concentration did not differ significantly before and after BDM. Therefore, it is unlikely that difference in plasma NE concentration caused by BDM infusion might affect the cardiac contractile efficiency during cardiac sympathetic stimulation.

In summary, the present study showed that $\beta$-adrenergic activation by cardiac sympathetic stimulation increased cardiac contractility with NE release but decreased cardiac contractile efficiency through a mechanism by which crossbridge formation of contractile proteins was augmented in cardiac muscle cells.

\section{Acknowledgments}

We are grateful to Dr Kogo Onodera, ex-professor of our department, for his helpful advice regarding this manuscript. We also appreciate the valuable comments on this study from Hiroyuki Hanada, MD, Yasuhiro Fujino, MD, and Nobuyo Shinozaki, PhD.

\section{References}

1. Applegate JR, Little CW: Alteration of autonomic influence on left ventricular contractility by epicardial superfusion with hexamethonium and procaine. Cardiovasc Res 1994; 28: 1042-1048

2. Levy NM, Blattberg B: Progressive reduction in norepinephrine overflow during cardiac sympathetic nerve stimulation in the anaesthetized dog. Cardiovasc Res 1976; 10: 549-555

3. Wallick WD, Martin JP, Masuda Y, Levy NM: Effects of autonomic activity and changes in heart rate on atrioventricular conduction. Am J Physiol 1982; 243: H523-H527

4. Nobuharu Y, Jacques CD, Reginald N: Correlation between the response of the heart to sympathetic stimulation and the release of endogenous cathecolamines into the coronary sinus of the dog. Circ Res 1975; 36: 662-668

5. Warner RM, Senanayake DP, Ferrario WC, Levy NM: Sympathetic stimulation-evoked overflow of norepinephrine and neuropeptide Y from the heart. Circ Res 1991; 69: 455-465

6. Miyahara K, Mikuniya A, Hanada H, Kanazawa T, Onodera K, Shinozaki N: Effect of inferior vena cava occlusion on left ventricular end-systolic pressure-volume relations in intact canine hearts. Jpn Circ J 1996; 60: 652-661

7. Murakami M, Mikuniya A, Suto N, Okubo T, Shinozaki N, Okumura $\mathrm{K}$ : Effect of cardiac sympathetic nerve stimulation on the left ventricular end-systolic pressure-volume relationship and plasma norepinephrine dynamic in dogs. Jpn Circ J 1997; 61: 864-871

8. Joseph YF, Gunther H, Rossmanith JL, Hamilton AM: Adrenaline increases the rate of cycling of crossbridges in the rat cardiac muscle as measured by pseudo-random binary noise-modulated perturbation analysis. Circ Res 1988; 62: 452-461

9. Suga H, Hayashi T, Shirahata M: Ventricular systolic pressure 
volume area as predictor of cardiac oxygen consumption. Am J Physiol 1981; 240: H39-H44

10. Suga H: Total mechanical energy of a ventricle model and cardiac oxygen consumption. Am J Physiol 1979; 236: H498-H505

11. Suga H, Hayashi T, Suehiro S, Hisano R, Shirahata M, Ninomiya I: Equal oxygen consumption rates of isovolumic and ejecting contractions with equal systolic pressure-volume areas in canine left ventricles. Circ Res 1981; 49: 1082-1091

12. Alpert RN, Blachard ME, Mulieri AL: Tension-independent heat in rabbit papillary muscle. J Physiol 1989; 414: 433-453

13. Baan J, Aouw Jong TT, Kerkhof MLP, Moene JR, van DIJK DA, van der Velde TE, et al: Continuous stroke volume and cardiac output from intraventricular dimensions obtained with impedance catheter. Cardiovasc Res 1981; 15: 328-334

14. Baan J, van der Velde TE, de Bruin GH, Smeenk JG, Koops J, van Duk DA, et al: Continuous measurement of left ventricular volume in animals and humans by conductance catheter. Circulation 1984; 70: $812-823$

15. Gibbs CL, Chapman BJ: Cardiac energetics. In: Handbook of physiology (The cardiovascular system), vol. 1 (The heart), 1979: 775804

16. Gibbs LC, Chapman BJ: Cardiac mechanics and energetics: chemomechanical transduction in cardiac muscle. Am J Physiol 1985; 249: H199-H206

17. Suga H: Ventricular energetics. Physiol Rev 1990; 70: 247-277

18. Nozawa T, Cheng C, Noda T, Little CW: Relation between left ventricular oxygen consumption and pressure-volume area in conscious dogs. Circulation 1994; 89: 810-817

19. Suga H, Hisano R, Goto Y, Yamada O, Igarashi Y: Effect of positive inotropic agents on the relation between oxygen consumption and systolic pressure volume area in canine left ventricle. Circ Res 1983;
53: $306-318$

20. Burkhoff D, Yue TD, Oikawa YR, Franz RM, Schaefer J, Sagawa K: Influence of ventricular contractility on non-work-related myocardial oxygen consumption. Heart Vessels 1987; 3: 66-72

21. Suga H, Goto Y, Yasumura Y, Nozawa T, Futaki S, Tanaka N, et al: $\mathrm{O}_{2}$ consumption of dog heart under decreased coronary perfusion and propranolol. Am J Physiol 1988; 254: H292-H303

22. Wu D, Yasumura Y, Nozawa T, Tanaka N, Futaki S, Ogoshi Y, et al: Effect of ouabain on the relation between left ventricular oxygen consumption and systolic pressure-volume area (PVA) in dog heart. Heart Vessels 1989; 5: 17-24

23. Sasaki M, Mikuniya M, Onodera K: Experimental study on the relationship between ventricular energetics and myocardial oxygen extraction dynamics. Hirosaki Med J 1994; 46: 111-120

24. Nozawa T, Yasumura Y, Futaki S, Goto Y, Suga H: Relation between oxygen consumption and pressure-volume area of in situ dog heart. Am J Physiol 1987; 253: H31-H40

25. Higuchi $\mathrm{H}$, Takemori S: Butanedione monoxime suppresses contraction and ATPase activity of rabbit skeletal muscle. J Biochem 1989; 105: $638-643$

26. de Tombe PP, Burkoff D, Hunter WC: Comparison between the effect of 2,3-butanedione monoxime (BDM) and calcium chloride on myocardial oxygen consumption. J Mol Cell Cardiol 1992; 24: 783 797

27. Takasago T, Goto Y, Kawaguchi O, Hata K, Saeki A, Suga H: 2,3butanedione monoxime suppresses excitation-contraction coupling in the canine blood-perfused left ventricle. Jpn J Physiol 1997; 47: $205-215$

28. Yaku H, Slinler KB, Mochizuki T, Lorell HB, LeWinter MM: Use of 2,3-butanedione monoxime to estimate nonmechanical $\mathrm{VO}_{2}$ in rabbit hearts. Am J Physiol 1993; 265: H834-H842 